Tourism Economics, 2009, 15 (4), 825-846

\title{
Customer satisfaction with and loyalty towards online travel products: a transaction cost economics perspective
}

\author{
YEONG GUG KIM AND GANG LI \\ School of Management, University of Surrey, Guildford, Surrey GU2 7XH, UK. \\ E-mail:y.kim@surrey.ac.uk; g.li@surrey.ac.uk.
}

\begin{abstract}
This study examines the usefulness of the theory of transaction cost economics (TCE) for the online travel market and investigates customer satisfaction and loyalty with the transaction cost over the Internet taken into account. Using structural equation modelling (SEM), the authors identify the relationships among the antecedents (uncertainty, personal security and buying frequency), the mediating variable (transaction costs) and endogenous constructs (customer satisfaction and loyalty). The findings suggest that the satisfaction and loyalty of customers purchasing travel products over the Internet are affected negatively by transaction costs, which are determined by uncertainty, personal security and buying frequency. Moreover, a significantly negative relationship is identified between buying frequency and customer satisfaction.
\end{abstract}

Keywords: transaction cost economics; TCE; transaction costs; online travel products; satisfaction; loyalty

The advent of information technology (IT) enables easy access to product information by both suppliers and buyers, provides transaction assurance and solves timely problems for business applications and convenience (Bakos, 1997; Buhalis and Licata, 2002; Buhalis, 2003; Beldona et al, 2005). Thus, the size of electronic commerce (e-commerce), based on the advantage of IT, has been increasing continually. The tourism industry is no exception to this practice.

The tourism business environment has been undergoing a major transition in which travel-related products increasingly have been offered over the Internet and traditional travel agencies have faced growing competition from a new breed of online intermediaries (Buhalis and Licata, 2002). Beldona et al (2005) indicated that traditional tour operators recognized the potential of this new

The authors wish to thank Dr Clark Hu and Dr Martin Y. Hyun for their helpful suggestions on initial research directions. They also wish to thank the anonymous reviewers for their constructive and valuable comments. 
distribution channel and viewed the Internet as the only way forward. According to Euromonitor (2007), online sales in the UK accounted for a $19.5 \%$ share of the global retail travel market in 2006, the majority of which were made via online travel agents. It was also reported that online bookings increased from 7\% in 2002 to 35\% of all bookings in 2006 (Euromonitor, 2007). Additionally, travel remains the largest online retail category, growing from US $\$ 63$ billion in 2005 to a projected US $\$ 119$ billion in 2010 worldwide (ITAA, 2005).

Purchasing travel products over the Internet is predominantly beneficial for both service providers and buyers, because using Internet travel services creates value for consumers through enhanced goods and services, reduced costs and immediate communication with service providers (Kim et al, 2007). A plethora of online information sources allows potential travellers to selfadminister various travel planning with less effort than the traditional sources, such as high street travel agencies (Buhalis, 2003; Bai et al, 2004). Chu (2001) suggests that online shopping for travel products enables a consumer to find combinations of products and services at a reasonable price in the shortest delivery lead-time. During the buying process, a consumer often undertakes a variety of activities, such as searching for information, negotiating terms and monitoring the ongoing process, so that a favourable deal can be negotiated with cheaper transaction costs (Liang and Huang, 1998; Teo and Yu, 2005).

From the perspective of transaction cost economics (TCE), transaction costs are defined as those costs incurred in making an exchange and are considered as a major factor in business transactions (Coase, 1937; Williamson, 1981, 1985). Empirical studies on TCE demonstrate that minimizing transaction costs associated with asset specificity, uncertainty and transaction frequency results in a profit among economic actors in either traditional or online markets (Liang and Huang, 1998; Teo and Yu, 2005). They further argue that information existing on the Internet can reduce information asymmetry related to transaction costs and the reduced information asymmetry can ensure transaction transparency and reduced transaction costs. Thus, the online market that has lower transaction costs can be accepted as a preferred channel by the consumer (Liang and Huang; 1998; Teo and Yu, 2005).

Travel products feature intangible services. This intangible nature is associated with consumers' different decision-making processes and differentiated transaction costs in the online market, compared to online shopping for other tangible goods. Due to the intangible nature of travel products, travellers generally search for as much information as they can to reduce the perceived risk (Buhalis, 2003; Bai et al, 2004; Beldona et al, 2005). Therefore, the opportunity cost of searching time is higher. However, Bai et al (2004) argues that the Internet provides travellers with travel information about accommodation, tourist attractions and prices, and carries out the transaction online at the same time. This helps travellers reduce transaction costs by saving time and money, compared to the use of traditional travel distribution channels. It is therefore necessary to study the unique features of online transactions of travel products from the TCE perspective. However, despite the reduced transaction costs in e-commerce, which is one of the crucial strengths of customer benefits, few have attempted to address that the Internet can be 
regarded as a preferred channel for customers because of this reason (Liang and Huang, 1998; Teo and Yu, 2005).

Therefore, this study adopts the concept of TCE to understand online transactions of travel products by examining the structural relationships among uncertainty, buying frequency, online trust, transaction costs, customer satisfaction and loyalty in the online travel market. Furthermore, the study investigates whether or not reduced transaction costs can enable consumers to accept the online market as a potentially efficient channel for purchasing travel products.

\section{Literature review}

\section{Transaction cost economics}

TCE originates from the 'new institutional economics' paradigm, which has superseded some parts of traditional neoclassical economics. According to the theory of classical economics, a transaction is conducted without any cost in the market because the information available to a seller and a buyer is symmetrical (Teo and Yu, 2005). However, Coase (1937), who proposed the transaction cost theory, indicated that information between economic actors participating effectively in economic activities in a form of either business to business (B2B) or business to consumer (B2C) was only partial in the real market. In other words, Coase viewed transaction costs as having an interorganizational relationship among the economic actors. Coase suggested that the costs of conducting economic exchange in a market might exceed the costs of organizing the exchange between participants. In other words, transition costs result from those in the contracting process between suppliers and buyers. During this exchange process, both parties gather information on their counterparty, evaluate the alternative options, negotiate leading to transact, enforce contracts and the behaviour-related transaction, and monitor a contractor. All these activities incur additional costs to ensure a proper completion of the transaction.

The theory of TCE is associated prominently with Williamson, who explained the existence of the market economy in terms of internalizing transaction costs between parties (Williamson, 1981, 1985). Williamson developed Coase's work by proposing that transaction costs contained both the direct cost, such as managing relationships, and the possible opportunity costs, such as making inferior governance decisions. Williamson (1979, p 239) supposed that 'when a relatively abstract level of explanation is adopted, transaction costs seem to increase with increasing uncertainty, with the frequency of recurring transactions, and perhaps most importantly, the necessity to rely on transaction-specific assets'. More specifically, Williamson argued that transaction costs, born in an exchange relationship, were consequences of the complexity and the uncertainty of the economic system associated with human nature and differences in the character of the exchange level.

The human nature as suggested by Williamson includes bounded rationality and opportunism and is considered as the assumption of TCE. Meanwhile, differences in the characters of the exchange levels containing uncertainty, asset 
specificity and buying frequency are regarded as the antecedents of transaction costs. Therefore, the framework of TCE builds on the interplay between two main assumptions of human behaviour and three dimensions of transaction.

TCE begins with considering economic actors as boundedly rational and opportunistic (Williamson, 1981, 1985). The theory of classical economics considers economic actors as rational decision makers. However, Williamson believed that individuals had limited memories and limited cognitive processing power. In other words, even though economic actors intend to act rationally, this intention might be confined by their imperfect information and an imperfect ability to process the available information. Thus, TCE argues that bounded rationality poses a problem in circumstances of complexity surrounding uncertainty, which represents the unpredictable outcome caused by information asymmetry in the transaction process. Uncertainty is regarded to have a direct effect on a decision making-related transaction (Williamson, 1981, 1985). There are two kinds of uncertainty: environmental uncertainty and behavioural uncertainty. Environmental uncertainty refers to changes in the external environment, which are unaffected by economic activities. In other words, environmental uncertainty surrounding the underlying transaction arises from changing conditions in random acts of nature and/or the economic environment in technology, competition and regulations. Thus, the economic actor cannot contract a comprehensive agreement which makes provisions for an uncertain future; whereas, there will be considerable transaction costs associated with ongoing renegotiations. Behavioural uncertainty refers to the inability of economic actors to foresee the intentions and actions of potential counterparties in the contracting process (Williamson 1981, 1985; Anderson, 1988). That is, behavioural uncertainty results from the lack of knowledge about the actions or decision rules of economic actors. Anderson (1988) viewed behavioural uncertainty as arising from difficulties associated with monitoring the contractual performance of exchange partners. For instance, if an economic actor had no incentive at all to carry out an agreement after making a contract, another contractor would need additional costs of monitoring a counterparty behaviour. Williamson (1985) further added that, even though the counterparty's future activities somehow could be expected, the information gathering and processing costs could be incurred by the human nature of economic actors.

Opportunism assumes that, given the situation, economic actors in a transaction relationship might seek their self-interest (Williamson, 1985). Williamson (1985, p 47) defined opportunism as 'self-interest seeking with guile'. He also considered that individuals might be distrustful about others' intentions and have an inclination toward taking advantage in unforeseen environments. Opportunism poses problems to the extent that a relationship is supported by specialized assets (Williamson, 1985). Generally, assets include knowledge for performing a service, machinery for manufacturing a product and a suitable site convenient for dealing with other economic actors. While specific assets are regarded to be locked into a particular exchange relationship, such a specific asset which meets a particular customer's needs cannot be offered to others (Williamson, 1985). For example, a customer who receives a special benefit, such as a cash-back bonus or mileage service from a specific service provider, may have difficulty in replacing the service provider with a new one. 
However, the service provider can exploit the circumstances opportunistically by taking advantage of the vulnerability of the customer. Hence, asset specificity creates a safeguarding problem because market competition no longer serves as a restraint for opportunism.

In addition, Williamson $(1981,1985)$ included buying frequency as a third transactional dimension. Buying frequency with exchanges refers to the number of times that an economic actor has dealings. Higher levels of buying frequency provide an incentive for economic actors to have 'in-house' provisions of goods and services (Teo and Yu, 2005), so-called 'hierarchical governance' because 'the costs of specialized governance structures will be easier to recover for large transactions of a recurring kind' (Williamson, 1985, p 60). For instance, when entering into an agreement with a new counterparty, there will be transaction costs such as gathering information, evaluating options and negotiating costs. However, when making a renewal or another contract with the same counterparty, these contractors can reduce transaction costs in the current process compared to the previous one, because they have already had information about each other, and a close relationship can reduce the perceived risk of opportunism. Therefore, Pitt and Foreman (1999) indicated that economic actors had intention to keep long-term relationships with others in order to reduce the recurring superfluous costs.

Table 1 summarizes the previous related research on TCE, where assumptions about human characteristics, that is, bounded rationality and opportunism, are linked with the level of the circumstance such as asset specificity, uncertainty and frequency.

\section{Transaction costs and e-commerce}

Over the past two decades, several theoretical and empirical studies have been published bearing either directly or indirectly on transaction costs in e-commerce (Liang and Huang, 1998; Meas et al, 1999; Teo and Yu, 2005; Morton, 2006). These studies identified that e-commerce had become an increasingly popular alternative to traditional forms of commerce. One of the key reasons for this is that under the same circumstance, ceteris paribus, a rational consumer chooses the channel incurring lower transaction costs. In particular, several previous studies demonstrated that adoption of IT had an effect on creating low transaction costs in e-commerce.

Malone et al (1987) examined the effects of the usefulness of IT on market structure and business strategies by using a transaction cost approach. They found that the innovations of IT contributed to reducing time and transaction costs for processing and communicating information. Additionally, these innovations also enabled individuals' and firms' concern about uncertainty of products and services to be diminished. Bakos (1997) explored whether or not the information search cost could be reduced in the e-market. The findings suggested that e-market systems enabled buyers to reduce costs for searching and acquiring information about product prices and offerings. Picot et al (1997) also suggested that a direct online contact between service providers and consumers could save more time than a physical visit to a service provider, and thereby reduce transaction costs. Strader and Shaw (1999) identified that online markets took transaction costs' advantages over traditional markets. Their 
Table 1. Cases of research on transaction cost economics.

$\begin{array}{ll}\text { Author } & \text { Variable } \\ \text { Masten et al (1991) } & \begin{array}{l}\text { Asset specificity } \\ \text { Environmental uncertainty }\end{array}\end{array}$

Sriram et al (1992)

Asset specificity

Perceived transaction costs

Bucklin and

Sengupta (1993)

Maltz (1993)

Maltz (1994)

Stump and Heide (1996)

Liang and Huang (1998)

Phau and Poon (2000)

Goldsmith and Goldsmith (2002)

Wilson and Zhang (2002)

Morrill and Morrill (2003)

Aubert et al (2004)

Teo and Yu (2005)
Asset specificity

Uncertainty

Business skill

Technical skill

Asset specificity

Uncertainty

Frequency

Asset specificity

Behavioural uncertainty

Frequency

Asset specificity

Frequency

Asset specificity

Partner qualification

Monitoring

Asset specificity

Uncertainty

Transaction cost

Frequency

Low cost

Transaction cost

Transaction cost

Uncertainty

Asset specificity

Transaction cost

Frequency

Uncertainty

Trust
Environmental uncertainty

\section{Summary of findings}

Asset specificity and environmental uncertainty are related positively to internal production of components.

Supplier-specific investments are related negatively to perceived buyer dependence and perceived transaction costs are related positively to propensity to collaborate.

Expected transaction-specific investments and expected frequency of interaction are associated positively with power imbalance.

Only human-specific assets are related positively to level of private fleet use.

Specific assets are related negatively to outsourcing, while frequency is related positively to outsourcing.

Buyers protect specific investments through partner selection and supplier-specific investments.

Consumer acceptance is determined by the transaction cost, which is related to uncertainty and asset specificity.

People are more likely to buy low-cost and frequently purchased products.

Low transaction cost has a positive effect on purchasing online.

Along with the transaction cost perspective, the capabilities-based perspective can provide a useful way of examining contracting issues related to the sales force and can predict contracting decisions.

Asset-specific investment and uncertainty are associated significantly with audit participation.

Uncertainty is the major deterrent to outsourcing, while the level of technical skills is the most important reason to outsource. Asset specificity, which is always presented as a constraint to outsourcing, shows inconsistent effects.

Customers' willingness to buy online is associated negatively with perceived transaction costs related to uncertainty and frequency. 
findings showed that consumers benefited from online markets in terms of lower search costs through the abundant information on the Internet.

Moreover, Meas et al (1999) reported that the World Wide Web represented an increasingly important source of information available among the market participants and could help to solve the problem of information asymmetry. Thus, the e-commerce system has already been reducing transaction costs in a diversity of business processes, and low transaction costs can allow economic actors to perceive e-commerce as a potentially efficient channel for an exchange market. Similarly, IT helps to reduce information asymmetry and allows consumers to save the monitoring cost of the online purchasing processes, such as delivery dates and/or a status of product delivery (Konana et al, 2000). Surjadjaja et al (2003) pointed out that the primary motivation of service providers toward trading in e-commerce was to reduce transaction costs. They also noted that the existence of a variety of information over the Internet could likely enable a reduction in overall transaction costs. Morton (2006) indicated that the Internet provided information so that buyers could obtain price quotes quickly and easily from various service provides, which allowed consumers to pay a lower price and save transaction time when buying products.

From a TCE perspective, studies have emphasized the importance of transaction costs in e-commerce by identifying the effect of transaction costs, determined by uncertainty, asset specificity and buying frequency, on consumers' online purchasing behaviour in e-commerce (Liang and Huang, 1998; Teo and Yu, 2005). Liang and Huang (1998) attempted to develop a TCE framework for measuring the relationships between two antecedents of transaction costs (that is, uncertainty and asset specificity): transaction costs (that is, comparison, examination, negotiation, payment, delivery and postservice cost) and consumers' acceptance. They found that solving the problem related to information asymmetry was considered a key element, which lowered transaction costs (Liang and Huang, 1998). Liang and Huang's contribution can be seen from developing the customer online acceptance model based on TCE, but they do not present the relationship between buying frequency and transaction costs. Subsequently, Teo and Yu (2005) modified Liang and Huang's model to examine customer willingness to buy online products by adding online trust and buying frequency as exogenous variables. They demonstrated that the perceived transaction costs were associated with uncertainty, trust and buying frequency in online stores. This evidence indicates that high transaction costs impact negatively on a customer's intention to shop online. Both studies concluded that consumers' positive perceptions and willingness to purchase online products resulted from lower transactional costs. Therefore, TCE can play an important role in attracting online shopping (Liang and Huang, 1998; Teo and $\mathrm{Yu}, 2005)$.

To the best of our knowledge, there has not been any study which has applied the TCE framework to the online travel market. Given the increasing popularity and importance of online purchase of travel products and the unique features of travel products, such a study has important implications for online distributors of travel products and services. It is therefore necessary to bridge this gap in the literature. 


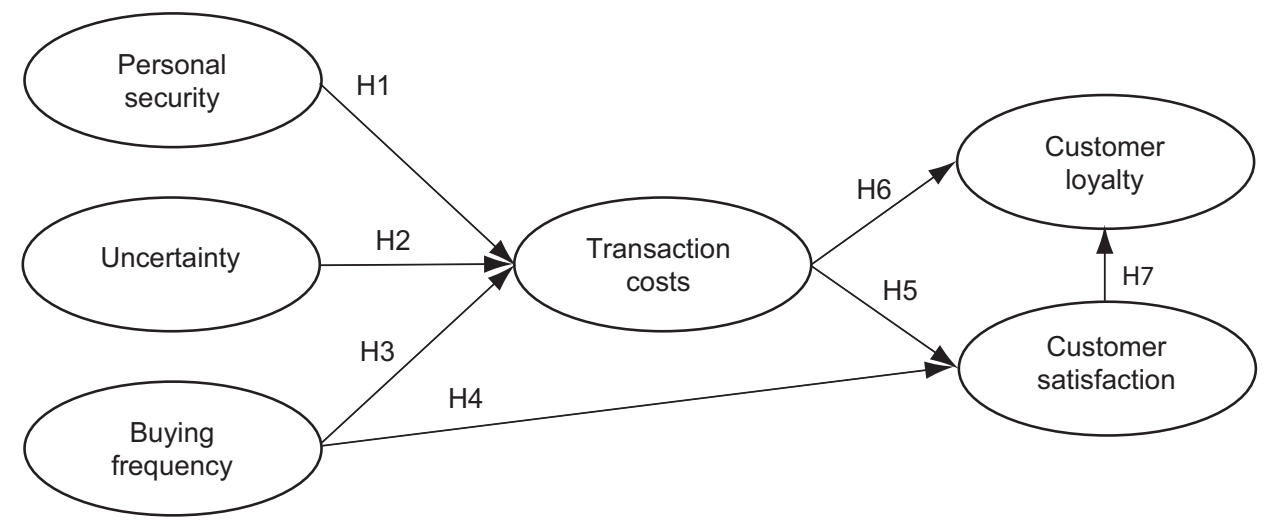

Figure 1. The proposed model.

\section{Proposed model and research bypotheses}

Based on the literature review above, this study proposes a model to examine the relationship between variables in the TCE framework and consumer online shopping behaviour. Figure 1 presents the proposed model in which relevant constructs and hypotheses are specified. The relationships among the constructs in this model are tested empirically, for the first time, in the context of an online travel market.

The first hypothesis is on the relationship between personal security and transaction costs. This hypothesis is based on the fact that a high level of distrust of transactions in e-commerce is regarded as an obstacle in stimulating online shopping (Suh and Han, 2003; Teo and Yu, 2005). In particular, the issue of personal security has drawn much attention in e-commerce. From this point of view, Bhatnagar et al (2000) attempted to identify the risks in e-commerce. They showed that these risks were associated with consumer concern about financial transactions, such as transmitting credit card information on the Web. Miyazaki and Fernandez (2001) also showed both experienced and inexperienced users of online shopping considered information on privacy and personal security as a major concern. Similarly, Yoon (2002) illustrated that transactional security and an invasion of privacy over the Internet were key antecedents to online purchase decision. Suh and Han (2003) pointed out that security assurance, or payment system security which offered an assurance of transaction security, was an essential problem to be overcome. Teo and Yu (2005) also indicated that personal security was an influential factor of transaction costs.

H1. Personal security is associated with transaction costs.

The next set of hypotheses considers the relationships between two antecedents of transaction costs (that is, uncertainty and buying frequency) and transaction costs in e-commerce. Based on the theoretical background discussed above (for example, Williamson, 1981, 1985) and the results of the empirical studies from a TCE perspective (Liang and Huang, 1998; Teo and Yu, 2005), the current 
study measures their relationships in the travel online market. Therefore, the following hypotheses are proposed:

\section{$\mathrm{H} 2$. Uncertainty is associated with transaction costs.}

$\mathrm{H} 3$. Buying frequency is associated with transaction costs.

Furthermore, according to the law of diminishing marginal utility (Mankiw, 2004), as an individual increases consumption of goods and services, there is a corresponding decline in the marginal utility of such consumption. The utility refers to a measure of satisfaction or happiness (Mankiw, 2004). In other words, as consumption continues, an individual's satisfaction derived from consuming each additional unit of the same good or service diminishes. Several studies have shown that there are significant adverse relationships between long-term purchasing from the same service provider and the perception of customer satisfaction (Oliver and Burke, 1999; Ellinger et al, 1999). Accordingly, the fourth hypothesis is on the relationship between buying frequency and consumer satisfaction.

\section{H4. Buying frequency is associated with consumer satisfaction.}

The last set of hypotheses is about the relationships among transaction costs, customer satisfaction and loyalty. As suggested by past studies (Liang and Huang, 1998; Teo and Yu, 2005), a high level of transaction costs is related negatively to willingness to buy online. More specifically, several studies have revealed that online shopping intention and further behaviour are related positively to the reduced transaction costs which are identified as a significant advantage of online shopping (Woodruff and Gardial, 1996; Cannon and Homburg, 2001; Bharadwaj and Matsuno, 2006). For example, Woodruff and Gardial (1996) found that satisfaction mediated between transaction costs and customer loyalty. Cannon and Homburg (2001) identified a direct relationship between customers' procurement cost savings and their desire to increase future transactions. Bharadwaj and Matsuno (2006) also showed that low transaction costs influenced both customer satisfaction and customer retention positively.

The current study assesses the relationship between customer satisfaction and customer loyalty in regards to online shopping of travel products. Online consumer satisfaction has often been used to measure e-commerce success and its positive influence on consumer post-purchasing behaviours, such as customer loyalty and intention to repurchase (MacDonald and Smith, 2004). In particular, according to Oliver and Burke (1999), creating loyalty depends on meeting customers' satisfaction, which is affected by their expectations. Oliver and Burke further suggested that there was a significantly positive correlation between consumers' satisfaction and their future intentions. Several empirical studies have identified that customer satisfaction is a general antecedent of loyalty (MacDonald and Smith, 2004). These studies indicate that a customer cannot be loyal without being highly satisfied. Therefore, satisfaction is likely to be an important driver of customer loyalty in the business environment.

H5. Transaction costs are associated with customer satisfaction.

H6. Transaction costs are associated with customer loyalty.

H7. Customer satisfaction is associated with loyalty. 


\section{Research methodology}

\section{Sampling procedure}

South Korea was selected as the sampling location for this empirical study. South Korea retains 34 million Internet users, ranked 7 th in the world in terms of the number of Internet users as of December 2005 (IWS, 2007). Another source of statistics reported that $16 \%$ of the Korean population shopped online and spent US\$720 million in 2000 (KNSO, 2006). In addition, South Korea has pursued the rapid development of IT and networks. Companies are engaged increasingly in various e-businesses. The total sales in the e-commerce market in South Korea was estimated to reach US $\$ 358.45$ billion in 2005 and online sales accounted for about $20 \%$ of the total sales in the country (KNSO, 2006). Given the popularity and fast development of e-commerce in South Korea and the relatively mature e-market, it is believed that the findings of this research have important implications for both the Korean online travel market specifically and e-tourism distribution in general.

In order to obtain effective measurement tools, an expert review and a pilot survey were conducted in this study. The expert review process resulted in a set of 25 items remaining out of the original 30 to represent the research model. In the next stage, a pilot survey was carried out on a convenience sample of 50 postgraduate students in the beginning of July 2006 and a total of 43 usable responses were obtained. These respondents self-reported that they were regular Internet users and had made online purchases 6 months prior to the survey. The survey findings revealed that the values of Cronbach's $\alpha$ for all constructs were in the range between 0.661 and 0.903 , higher than 0.60 , evidencing relatively high reliability (Hair et al, 2006). Based on the feedback from the pilot survey, a final questionnaire was developed with minor modifications.

The web-based online convenient sampling method was finally adopted to obtain the data for the main study. This sampling method was chosen for three reasons. Firstly, the online survey is useful to identify the relationship between using the Internet and the intention of purchasing online products; secondly, the web-based survey is designed with low costs and high usability to increase the response rate (Kim et al, 2007); and thirdly, online surveys enable easier access to those hard-to-reach populations (such as online communities) via other channels of data collection (Wright, 2005). Therefore, given that probability sampling is practically infeasible for most social science studies, it is believed the online survey is the most suitable sampling method for this study. As Stanton (1998) concludes, online surveys exhibit no more danger than other sorts of non-probability sampling in terms of their potential for self-selection bias.

The online questionnaire was set up on an online survey website. The questionnaire was placed on this website for around 50 days from 10 July to 31 August 2006 in South Korea. An e-mail invitation, which explained the aims of this study and contained the link to the web-based survey, was distributed to members on the mailing list of this online survey website. Members who received an invitation participated in this research on a voluntary basis. To encourage their responses, participants were provided with financial incentives (that is, cyber money) by the survey website. The participants were 
Table 2. Operational constructs and references.

\section{Construct Operational definition}

Uncertainty

The unexpected outcome and asymmetry of information in e-commerce.

Personal security

Policies, procedures and technical measures used to prevent unauthorized access or physical damage to personal information in e-commerce.

Buying frequency The number of times that a customer buys products.

Searching cost

Comparing cost

The cost incurred at the stage of finding a product in e-commerce.

The cost incurred at the stage of comparing alternatives based on their attributes in e-commerce.

Monitoring cost

The cost incurred after ordering or receiving a product, such as maintenance and customer support in e-commerce.

Overall satisfaction How pleased the customer is with the services provided in e-commerce.

Customer loyalty The behaviour that customers exhibit when making frequent repeat purchases in e-commerce.

\section{References}

Liang and Huang (1998);

Aubert et al (2004);

Teo and $\mathrm{Yu}(2005)$

Bhatnagar et al (2000);

Suh and Han (2003);

Teo and $\mathrm{Yu}(2005)$

Teo and Yu (2005)

Liang and Huang (1998);

Teo and $\mathrm{Yu}(2005)$

Liang and Huang (1998)

Liang and Huang (1998);

Teo and $\mathrm{Yu}(2005)$

MacDonald and Smith (2004)

MacDonald and Smith (2004)

asked to complete the self-administered online questionnaire based on their experience of purchasing travel products over the Internet during the past 3 years. In particular, only shoppers who bought travel products online were considered as valid respondents, given the objectives of this study (Donthu and Garcia, 1999). A total of 1,000 questionnaires were collected and 469 responses were employed finally for the empirical investigation after eliminating nonshoppers' data and invalid responses.

\section{Measurement of constructs}

Constructs in the model were developed based on the theory suggested by Williamson $(1981,1985)$ and they were measured basically on a scale developed by Liang and Huang (1998) and Teo and Yu (2005). The proposed model thus has six constructs: uncertainty, personal security, buying frequency, transaction costs, customer satisfaction and customer loyalty. The current study focused on the perceived information of customers, because it seemed to be difficult to gather the actual cost data incurred in a transaction over the Internet. Thus, the perceived information, leading to customer decisions due to the bounded rationality, became a major focus of this study. Constructs of the proposed model were operationalized based on the extensive review of the literature, with modifications and developments in the context of tourism research. The definitions of construct measures developed in this study are provided in Table 2 . 
With respect to personal security, this can be defined as physical damage to personal information over the Internet (Suh and Han, 2003; Teo and Yu, 2005). Although personal security was not considered in the original TCE (Williamson, 1981, 1985), this measure was operationalized based on the concern that leaking personal security can be an obstacle in stimulating online shopping. Thus, this study employed four items to measure personal security, with a fivepoint Likert-type scale ranging from strongly disagree $=1$ to strongly agree = 5: 'online purchasing of travel products is transactionally secure'; 'online personal information is systematically kept confidential'; 'a policy statement will not be released without the customer's consent'; 'travel agencies on the Internet require too much personal information when logging in'. In a transaction, uncertainty can be regarded as asymmetry of information provided in online travel agencies (Liang and Huang, 1998). Because of uncertain information, the customer has a feeling of uneasiness that the received product will not meet his or her expectation at ordering. This study developed three items of uncertainty measurement: 'travel agency's reliable information'; 'travel agency's sufficient information'; and 'travel products on the Internet are reliable'. The third antecedent, buying frequency, was measured by the number of purchasing times: 1 for once; 2 for 2 or 3 times; 3 for 4 or 5 times; 4 for 6 or 7 times; and 5 for more than 8 times.

Measures of transaction costs consisted of the three dimensions: searching cost, comparing cost and monitoring cost. Although Liang and Huang (1998) suggested six types of transaction costs - comparison, examination, negotiation, payment, delivery and post-service cost - they suggested that searching cost, comparing cost and monitoring cost were appropriate when considering the nature of online shopping. Thus, the measurement of searching costs consisted of the following items: 'purchasing travel products on the Internet saves time when searching for information'; 'purchasing travel products on the Internet reduces efforts to get information'; and 'I can purchase travel products at any time of the day'. For assessing comparing cost, this study used three items: 'I can compare the qualities of travel products'; 'travel agencies over the Internet offer more choice'; and 'online purchasing helps me to compare prices between different products'. Monitoring cost was also measured by three items: 'I can get a refund easily when having a problem with products'; 'online travel agencies deal quickly with problems related to the products'; and 'I spend a lot of time monitoring whether the product I purchased is processed well'.

Customer satisfaction and loyalty were measured on a combined scale that was developed based on the existing literature (MacDonald and Smith, 2004). The measurement items of customer satisfaction were associated with the expected outcome, derived from the information provided by online travel agencies: 'overall, I am satisfied with shopping on the Internet'; 'overall, I am satisfied with online shopping, when compared with expectation'; and 'overall, I am satisfied with online shopping when considering my invested time and effect'. Meanwhile, this study employed such items as repurchase intention and recommendation (Cannon and Homburg, 2001; MacDonald and Smith, 2004) to assess customer loyalty: 'I will recommend buying travel products over the Internet to others; and 'I will repurchase travel products on the Internet'. 


\section{Results}

The proposed model was verified using structural equation modelling (SEM) in order to illustrate, interrelate and explain the relationships among the dimensions. SEM allows more flexible assumptions, has the ability of testing models overall rather than coefficients individually, is able to model mediating variables and can handle difficult data (Anderson and Gerbing, 1988; Hair et al, 2006). The sample size of this study was sufficient to analyse the proposed model because the minimum sample size of 150 recommended by Anderson and Gerbing (1988) had been reached. Exploratory factor analysis (EFA) was conducted to identify factors relevant to the proposed model and then confirmatory factor analysis (CFA) was used to develop a good measurement model. Lastly, the proposed model was tested using SEM computed by AMOS 6.0

\section{Reliability and validity}

First of all, the test of the proposed model included the examination of reliability for internal consistency. Internal consistency was calculated using Cronbach coefficients and all constructs ranged from 0.66 to 0.90 , higher than the minimum cut-off score of 0.6 (see Table 3).

EFA with varimax rotation was undertaken to assess the underlying dimensions of the proposed model. To determine whether a particular data set is suitable for factor analysis, inspection of the strength of the relationship among the items is necessary. Hence, in order to investigate the structure of a set of variables and the data reduction, EFA was performed (Hair et al, 2006). The latent root criterion of 1.0 was used for factor inclusion and a factor loading of 0.40 was used as the benchmark to include items in a factor. The appropriateness of factor analysis was determined by the Kaiser-Meyer-Olkin $(\mathrm{KMO}=0.73)$ measure of sampling adequacy and Bartlett's test of sphericity $(p<0.000)$. The EFA resulted in seven factors derived from the 20 items. All factor loadings were greater than 0.50 at a very significant level, demonstrating a set of good correlations between the items and their factor (Hair et al, 2006). However, the following items were dropped because of unacceptably low communalities: 'travel agencies provide sufficient information' and 'difficulty to refund and change products' in the dimension of 'uncertainty'. Consequently, the properties of the proposed model were tested with the CFA procedure.

Prior to testing the SEM procedure, CFA of the proposed model was conducted to identify the unidimensionality. CFA provides adequate support for the proposed model based on EFA and it is a prerequisite of SEM analysis to identify the relationships between a set of observed variables and a set of continuous latent variables (Anderson and Gerbing, 1988). The result showed that each item reflected only one underlying construct and construct validity was confirmed. As a result of CFA, the overall fits of the proposed model met the criteria: RMSEA and SRMR $(<0.08)$; GFI, TLI and CFI $(>0.90)$, indicating that the model offered good fit to the data: RMSEA $=0.06$, SRMR $=0.06, \mathrm{GFI}=0.92, \mathrm{AGFI}=0.89, \mathrm{TLI}=0.91$ and $\mathrm{CFI}=0.92$.

Construct validity was examined by assessing convergent validity and discriminant validity (Ping, 2004). Convergent validity can be demonstrated by 
Table 3. Results of EFA and CFA.

Factors and items

Factor 1: Personal security

Purchasing travel products on the Web is transactionally secure

Online travel agencies require too much personal $\quad 0.73$ information when registering on the Web

Online personal information systematically maintains confidentiality

A policy statement will not be released without customer's consent

Factor 2: Comparison cost

Online purchasing helps me to compare prices among different products

Online travel agencies offer more choices

I can compare the qualities of travel products on the Web

Factor 3: Overall satisfaction

Overall, I am satisfied with shopping on the Web

Overall, I am satisfied with online shopping as much as I expected to be

Overall, I am satisfied with online shopping, considering the time and effort invested

Factor 4: Searching cost

Purchasing travel products online saves time when searching for information

Purchasing travel products online reduces the effort to get information

I can purchase travel products at any time of the day 0.70

Factor 5: Monitoring cost

I spend a lot of time monitoring whether

purchasing products are processed well

When having a problem related to products,

travel agencies over the Internet deal with the problem quickly

When having a problem related to products, I can get a refund easily

Factor 6: Customer loyalty

I will repurchase travel products on the Web

I will recommend others to buy travel products over the Internet

Factor 7: Uncertainty

Travel products on the Web are reliable

Travel agencies over the Internet offer reliable information about products $0.63^{\mathrm{a}}$

0.70

0.68

EFA

CFA

Factor Eigenvalue Std. loadings SMC loadings (variance ( $t$-value) explained)

$\begin{array}{cccc}0.83^{\mathrm{a}} & & & 0.62^{\mathrm{b}} \\ 0.85 & 2.82 & 0.99(12.69) & 0.95 \\ & (12.28) & & \\ 0.73 & & & \\ & & 0.74(13.35) & 0.56 \\ 0.73 & & 0.60 & 0.36\end{array}$

0.68

Deleted

$0.88^{\mathrm{a}}$

0.90

2.56

(11.11)

0.87

0.74

$0.77^{\mathrm{a}}$

0.75

0.73

2.02

(8.79)

$0.74(12.35)$

0.52

0.87 (18.68) 0.76

0.76

0.57

0.70

$0.71(12.21) \quad 0.51$

0.72

0.51

$0.75^{\mathrm{a}}$

0.82

1.61

(7.02)

0.72

$0.70(10.40)$

$0.50^{\mathrm{b}}$

$0.82(11.43) \quad 0.67$

0.58

0.34

$0.46^{\mathrm{b}}$

1.46

(6.35)

$0.67(9.88)$

0.51

0.67

0.40

0.57

Deleted

$0.81^{\mathrm{a}}$

0.93

0.73

1.23

(5.36)

0.84 (11.06)

$0.68^{\mathrm{b}}$

0.81

0.70

0.65

$0.81^{\mathrm{a}}$

$0.69^{\mathrm{b}}$

0.83

$1.05(4.56)$

$0.99(17.48)$

0.98

0.78

0.63

0.40

Note: ${ }^{a}$ Cronbachs alpha; ${ }^{b}$ average variance extracted (AVE). SMC refers to the squared multiple correlation. EFA: Kaiser-Meyer-Olkin measure of sampling adequacy $=0.73$; Bartlett's test of sphericity $p<0.000$; CFA: $\chi^{2}=365.287, p=0.00, d . f .=132, \mathrm{GFI}=0.92, \mathrm{AGFI}=0.89, \mathrm{TLI}=0.91, \mathrm{CFI}=0.92, \mathrm{RMSEA}=$ 0.06 , standardized RMR $=0.06$. 
Table 4. Construct validity of the proposed model: a correlation matrix.

1

$$
0.62
$$

1. Personal security

$-0.22$

0.08

0.13

0.28

0.06

$-0.11$

2

2. Comparing cost
3. Overall satisfaction
4. Searching cost
5. Monitoring cost
6. Customer loyalty
7. Uncertainty

2. Comparing cost
3. Overall satisfaction
4. Searching cost
5. Monitoring cost
6. Customer loyalty
7. Uncertainty
2. Comparing cost
3. Overall satisfaction
4. Searching cost
5. Monitoring cost
6. Customer loyalty
7. Uncertainty

2. Comparing cost
3. Overall satisfaction
4. Searching cost
5. Monitoring cost
6. Customer loyalty
7. Uncertainty

2. Comparing cost
3. Overall satisfaction
4. Searching cost
5. Monitoring cost
6. Customer loyalty
7. Uncertainty
3
4

5
6

7

0.70
-0.01
-0.42
-0.47
-0.02
0.12

\subsection{2 \\ 0.08 \\ 0.06 \\ 0.55 \\ $-0.02$}

0.50

0.37

0.03

0.46

0.15

0.68

0.01

0.02

0.69

showing internal consistency referring to the degree of interrelatedness among the observed items by using unidimensionality, composite $\alpha$ and average variance extracted (AVE). Discriminant validity refers to the cross-construct correlations among measures of causally related variables and should be highly intercorrelated, but correlated at a lower level than that of the within-construct correlations (Ping, 2004). Thus, internal consistency should always be higher than the measure distinctness. Unidimensionality was demonstrated through the evidence that every estimated loading of a measure on a construct was significant. As shown in Table 3, convergent validity is demonstrated by the composite $\alpha$ s varying from 0.63 to 0.88 and AVEs ranging from 0.46 to 0.70 .

Moreover, discriminant validity was evident since the squared values of AVE were greater than the correlation coefficients between any pairs of constructs (see Table 4). Therefore, a seven-construct structural model was accepted as a measurement model in this study. This structural model was examined further to test the hypotheses.

\section{Goodness-of-fit of the proposed model}

With confidence established in the proposed measurement model, a structural equation model was applied to the research model. The scale for each factor was set by fixing the factor loading to one of its indicator variables and then the maximum likelihood (ML) estimation method was applied. The model is presented in Figure 2, along with the estimates of standardized regression coefficients, factor loadings and residual variances and covariances. Despite the statistical significance of the path coefficients, they should be interpreted with caution due to the use of the survey response method. It should also be noted that the data are cross-sectional, so that the directions of the effects in the model are supported ultimately by the theory underpinning the linkages of the model.

The results suggested that all structural regression coefficients presented in the model were statistically significant. Although the chi-square value $\left(\chi_{(144)}^{2}\right.$ $=413.684, p=0.00)$ was not significant, other fit indices, GFI $=0.92$, AGFI $=0.89$, TLI $=0.90$, CFI $=0.92$, RMSEA $=0.063$ and SRMR $=0.061$, indicated that the model showed good agreement with the data. According to 


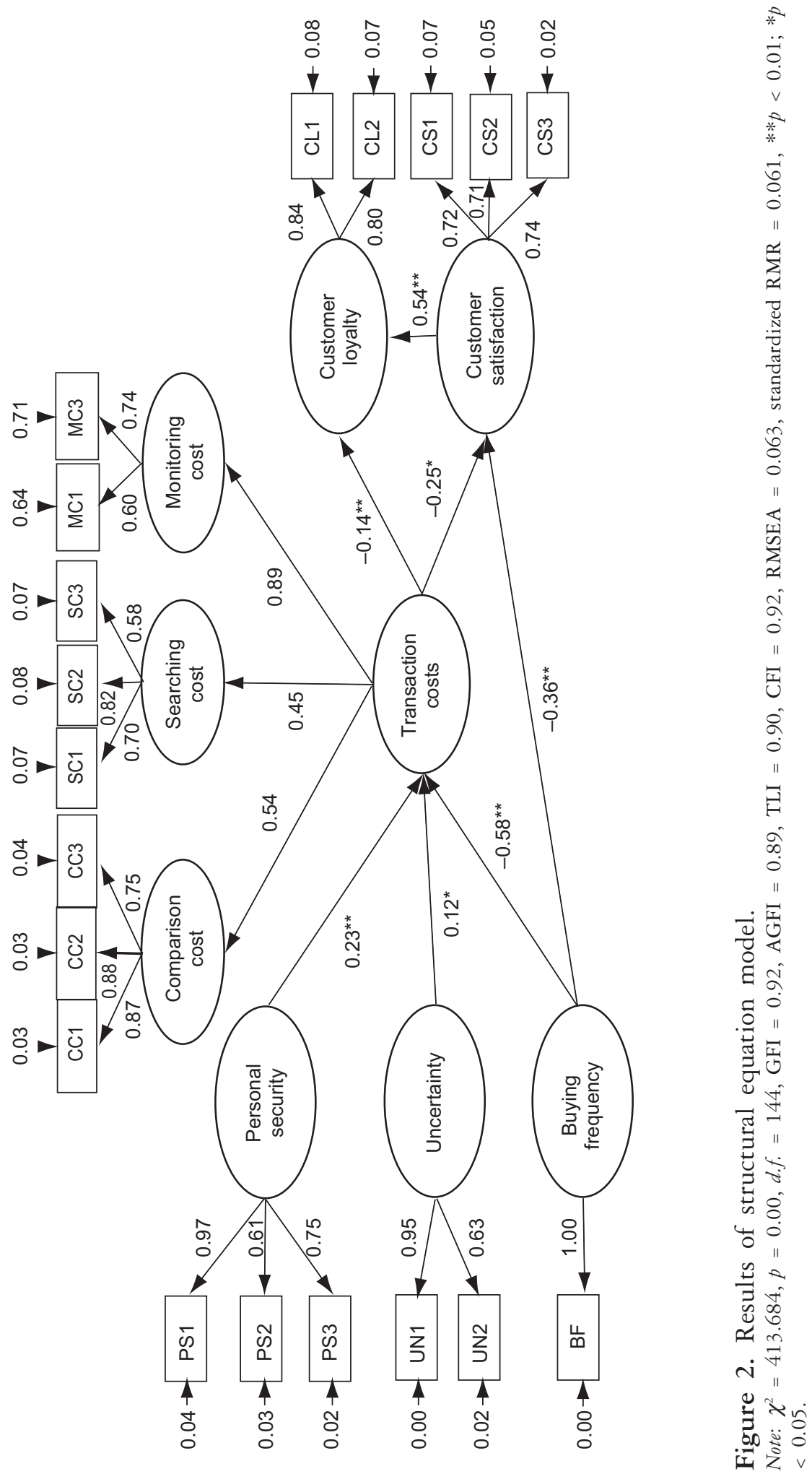


Hair et al (2006), one or more model fit indices are necessary to supplement the model evaluation because the chi-square is influenced by the sample size. Thus in this study, several types of overall model fit measures were employed: root mean square error of approximation (RMSEA), standardized root mean square (SRMR) and goodness-of-fit index (GIF), representing absolute fit indices.

Examination of the structural model determines whether the hypothesized relationships among latent constructs are accepted or rejected by showing significant coefficients. As presented in Figure 2, all of the hypothesized relationships were significantly accepted. The following paths were of positive directions: (i) personal security to transaction costs $(\beta=0.23, t=4.11)$; (ii) uncertainty to transaction costs $(\beta=0.12, t=2.86)$; and (iii) customer satisfaction to customer loyalty $(\beta=0.54, t=8.04$ ); while other paths were of negative directions: (iv) buying frequency to transaction costs $(\beta=-0.58$, $t=-8.12)$; (v) buying frequency to customer satisfaction $(\beta=-0.36, t=-4.76)$; (vi) transaction costs to customer satisfaction $(\beta=-0.25, t=-2.66)$; and (vii) transaction costs to customer loyalty $(\beta=-0.14, t=-2.40)$. The statistical results provided three major findings: (i) the antecedents of transaction costs - uncertainty and buying frequency - influence transaction costs directly in the context of tourism and personal security is newly identified as an antecedent of transaction costs over the Internet; (ii) buying frequency is in inverse proportion to customer satisfaction and it has both direct and indirect effects on satisfaction; and (iii) the transaction costs construct was found as a key mediating factor between uncertainty, personal security and buying frequency on the one hand and customer satisfaction and loyalty on the other hand, and it has negative effects on customer satisfaction and loyalty.

\section{Discussions and implications}

In line with previous research (Liang and Huang, 1998; Teo and Yu, 2005) which identified that uncertainty and buying frequency were important antecedents of transaction costs, this study further showed that these antecedents were significant influencing factors of transaction costs in the online travel market. In particular, uncertainty $(\beta=0.12, t=2.86$ ) had a significantly positive effect on transaction costs, while buying frequency $(\beta=-0.58$, $t=-8.12)$ affected transaction costs negatively. The findings of their relationships are also theoretically consistent with Williamson $(1981,1985)$. The negative relationship between buying frequency and satisfaction $(\beta=-0.36$, $t=-4.76$ ) also showed that a high level of buying frequency decreased the level of real satisfaction in the travel market. As argued by Oliver and Burke (1999), long-term transaction relationships may become less influential on customer satisfaction.

These findings provide important practical implications for the online travel market. Online travel agencies should actively monitor and reward customers in order to encourage them to revisit their websites and enhance their loyalty. Financial incentives such as a cash-back bonus, or loyalty programmes such as mileage service, should be considered to stop customers from switching to other online agencies. Since a high level of uncertainty with online travel agencies 
is one of the major factors increasing transaction costs, online travel agencies should pay particular attention to the ways and means of reducing the perceived uncertainty. For instance, they should endeavour to enhance information transparency with regard to the details of travel products and terms and conditions on order cancellation, payment and dispute resolution. Online travel agencies should regard communication with customers as an important factor in reducing uncertainty because, in the environment over the Internet, a lower level of communication with customers tends to lead to greater uncertainty. Therefore, increasing online travel agencies' contact and smooth communication with their customers contributes to improving consumers' trust of online travel product suppliers and establishing a long-term relationship with them, which will further increase customers' satisfaction and their intentions to repurchase.

This study identified personal security assurance to be a key positive antecedent of transaction costs in the online travel market $(\beta=0.23, t=4.11)$. This finding revealed that personal security assurance can contribute towards reducing transaction costs in e-commerce, consistent with the finding of Teo and $\mathrm{Yu}$ (2005). Regarding personal security, Suh and Han (2003) suggested that because some customers did not want to provide personal information and their credit card details over the Internet, they tended to be unwilling to purchase online products, in spite of the convenience of buying products on the Internet. Furthermore, with increased reliance on the Internet to carry out e-commerce, the possibility of computer misuse and abuse is also increasing. Therefore, online travel agencies should improve their reliability by developing a privacy policy, which enables consumers to understand clearly and signpost. Online travel agencies should also develop online surveillance systems, shorten the transactional process and create safe infrastructure for customers. Meanwhile, online travel agencies need to provide information about security and privacy issues, and this information should be accurate and easy to understand. In addition, online travel agencies should provide full information on customers' legal rights and liabilities for any losses should a fraudulent transaction occur. This information should convince customers to trust online agencies when giving any personal information.

As expected, the results showed transaction costs had a negative impact on customer satisfaction $(\beta=-0.25, t=-2.66)$ and loyalty $(\beta=-0.14, t=-2.40)$ with regard to online purchases. Furthermore, the relationship among transaction costs, customer satisfaction and loyalty coincided with the findings of Woodruff and Gardial (1996); that is, satisfaction mediates between transaction costs and loyalty. This finding supports the TCE theory that a rational economic actor or online traveller selects a transaction channel, which costs the least among all the available options (Williamson, 1981, 1985; Liang and Huang; 1998; Teo and Yu, 2005;).

The relationships between transaction costs and customer behaviour suggest that customers choose a shopping channel with low transaction costs and tend to be satisfied with the reduced transaction costs. This concern will affect consumers' decisions on purchasing online travel products. Therefore, online travel agencies should recognize that transaction costs, such as the search cost, comparison cost and monitoring cost, might change a consumer's buying behaviour. Thus, the online travel agencies should make an effort to attract and retain customers in order to reduce transaction costs. For example, they should 
display one overall total price to the consumer before the order is completed. In addition, value-added services such as assisting consumers in converting prices into their own currencies should be provided. This additional information will help the consumer considerably when deciding whether to make a purchase and these considerations can reduce consumers' perceived transaction costs of online shopping and improve the reliability of online travel products.

\section{Conclusions and future research}

The current study applies the theory of TCE to the online travel market and tests their contractual relationships empirically, which are likely to have effects on customer satisfaction and loyalty. Moreover, this study presents reliable confirmation that current knowledge of TCE can be extended to the travel online market. To summarize, this study makes the following contributions.

Firstly, the current study presents an initial attempt to apply the TCE framework to the online travel market. Although a number of studies have applied TCE to explain the rise of e-commerce and cost savings in e-commerce (Malone et al, 1987; Morton, 2006), very few studies (Liang and Huang, 1998; Teo and Yu, 2005) have investigated empirically the consumer's acceptance of online shopping from a TCE perspective. No empirical study has been found that examined this issue in the context of the online travel market. This study demonstrates that customers' purchasing behaviour of online travel products and services can be measured using a TCE approach.

Secondly, this study shows that the development of IT leading to information available on the Internet contributes to reducing information asymmetry and this abundant information can ensure transaction transparency and reduce transaction costs in the online market. More specifically, reduced information asymmetry in the online travel market allows searching cost, comparing cost and monitoring cost to be low. The study thus identifies that reduced transaction costs have a positive effect on a consumer's intention to purchase travel products. It shows empirical evidence that a rational economic actor or online traveller can evaluate the utility of the transaction channel and experience low transaction costs in the online travel market.

Thirdly, the current study identifies personal security as a new antecedent of transaction costs over the Internet. As discussed in the literature review, in an exchange process there are a buyer's concerns that a seller might take advantage by leaking personal information in the online market. This study shows the significant negative relationship between personal security and transaction costs in the online travel market.

Lastly, this study suggests that the transaction costs construct is a key mediator between uncertainty, personal security, buying frequency and customer satisfaction in the online travel market. In particular, transaction costs are perceived to have an effect on customer behaviours. Many previous studies have addressed the importance of transaction costs in exchange processes, but this study focuses on the role of reduced transaction costs between the antecedents of transaction costs and customer behaviours, such as satisfaction and loyalty. It demonstrates the mediating effect of transaction costs among the above constructs. 
The study presents a few limitations. Firstly, there may exist some selfselection bias regarding the online survey; that is, online sampling is biased to people who reply to the online survey. Therefore, some causation should be raised whenever there is an intention to generalize the findings of this study. However, examination of the demographic distribution of the sample showed no evidence that the bias may distort the conclusions drawn in this study. Moreover, as Wright (2005) notes, self-selection bias is also inherent in traditional data collection methods such as mailed surveys. Secondly, in this research design, the respondents were asked to identify the main travel agency for the product they purchased online. As a result, dissatisfied and disloyal customers may be slightly underrepresented. The variety of products with differing purchase cycles and product groups with different levels of competitive intensity could also have impacts on the findings. Thus, it is necessary that further research addresses these issues. Lastly, one of the objectives of this study was to identify the relationship between transaction costs and customer loyalty. Nevertheless, this study did not support this relationship. Although the role of satisfaction as the mediator between transaction costs and customer loyalty was found, further research is needed to examine the direct relationship between transaction costs and customer loyalty in the online travel market.

\section{References}

Anderson, E. (1988), 'Transaction costs as determinants of opportunism in integrated and independent sales forces', Journal of Economic Behavior and Organization, Vol 9, No 3, pp 247-264.

Anderson, J., and Gerbing, D. (1988), 'Structural equation modeling in practice: a review and recommended two-step approach', Psychological Bulletin, Vol 103, No 3, pp 411-423.

Aubert, B., Rivard, S., and Patry, M. (2004), ‘A transaction cost model of IT outsourcing', Information and Management, Vol 41, No 7, pp 921-932.

Bai, B., Hu, C., Elsworth, J., and Countryman, C. (2004), 'Online travel planning and college students: the spring break experience', Journal of Travel and Tourism Marketing, Vol 17, pp 7991.

Bakos, J.Y. (1997), 'Reducing buyer search costs', Management Science, Vol 43, No 12, pp 1676-1679.

Beldona, S., Morrison, A.M., and O'Leary, J. (2005), 'Online shopping motivations and pleasure travel products: a correspondence analysis', Tourism Management, Vol 26, No 5, pp 561-570.

Bharadwaj, N., and Matsuno, K. (2006), 'Investigating the antecedents and outcomes of customer firm transaction cost savings in a supply chain relationship', Journal of Business Research, Vol 59, pp 62-72.

Bhatnagar, A., Misra, S., and Rao, H.R. (2000), 'On risk, convenience, and Internet shopping behavior: why some consumers are online shoppers while others are not', Communications of the ACM, Vol 43, No 11, pp 98-105.

Buhalis, D. (2003) eTourism: Information Technology for Strategic Tourism Management, Prentice Hall, Harlow.

Buhalis, D., and Licata, M. (2002), 'The future of etourism intermediaries', Tourism Management, Vol 23, pp 207-220.

Bucklin, L.P., and Sengupta, S. (1993), 'Organizing successful co-marketing alliances', Journal of Marketing, Vol 57, pp 32-46.

Cannon, J.P., and Homburg, C. (2001), 'Buyer-supplier relationships and customer firm costs', Journal of Marketing, Vol 65, pp 29-43.

Chu, R. (2001), 'What online Hong Kong travelers look for on airline/travel websites?', International Journal of Hospitality Management, Vol 20, No 1, pp 95-100.

Coase, R.H. (1937), 'The nature of the firm', Economica, Vol 4, No 16, pp 386-405.

Donthu, N., and Garcia, A. (1999), 'The Internet shopper', Journal of Advertising Research, Vol 39, No 3, pp 52-58.

Ellinger, A., Daugherty, P., and Plair, Q. (1999), 'Customer satisfaction and loyalty in supply chain: 
the role of communication', Transportation Research Part E - Logistics and Transportation Review, Vol 35, No 2, pp 121-134.

Euromonitor (2007), 'Traditional tour operators fight back against online travel companies?' (http: //www.euromonitor.com/Traditional_tour_operators_fight_back_against_online_travel_companies, accessed 15 April 2008).

Goldsmith, R.E., and Goldsmith, E.B. (2002), 'Buying apparel over the Internet', Journal of Product and Brand Management, Vol 11, No 2, pp 89-102.

Hair, J., Black, B., Babin, R., Anderson, R., and Tatham, R. (2006), Multivariate Data Analysis, 6th edn, Prentice Hall, New York.

ITAA (2005), 'Forrester research US e-commerce forecast: online retail sales to reach $\$ 329$ billion by 2010' (http://www.itaa.org/isec/pubs/e20059-01.pdf, accessed 16 April 2008).

IWS (2007), 'Internet usage in Asia' (http://www.internetworldstats.com/stats3.htm, accessed 4 November 2007).

Kim, D.J., Kim, W.G., and Han, J.S. (2007), 'A perceptual mapping of online travel agencies and preference attributes', Tourism Management, Vol 28, No 2, pp 591-603.

Konana, P., Menon, N., and Balasubramanian, S. (2000), 'Exploring the implications of online investing', Communications of the ACM, Vol 43, No 1, pp 34-41.

KNSO (Korean National Statistical Office) (2006) Korean Statistical Yearbook, KNSO, Republic of Korea.

Liang, T., and Huang, J. (1998), 'An empirical study on consumer acceptance of products in electronic markets: a transaction cost model', Decision Support System, Vol 24, No 1, pp 2943.

MacDonald, J.B., and Smith, K. (2004), 'The effects of technology-mediated communication on industrial buyer behavior', Industrial Marketing Management, Vol 33, No 2, pp 107-116.

Malone, T., Benjamin, R., and Yates, J. (1987), 'Electronic markets and electronic hierarchies: effects of information technology on market structure and corporate strategies', Communications of the ACM, Vol 30, No 6, pp 484-497.

Maltz, A. (1993), 'Private fleet use: a transaction cost approach', Transportation Journal, Vol 32, pp $46-53$.

Maltz, A. (1994), 'Outsourcing the warehousing function: economic and strategic considerations', Logistics and Transportation Review, Vol 30, pp 245-265.

Mankiw, N.G. (2004), Principles of Economics, 3rd edn, Thomson, Mason, Ohio.

Masten, S.E., Meehan, J.W., and Snyder, E.A. (1991), 'The costs of organization', Journal of Law, Economics and Organization, Vol 7, pp 1-25.

Meas, P., Guttman, R.H., and Moukas, A.G. (1999), 'Agents that buy and sell', Communications of the ACM, Vol 40, No 3, pp 81-91.

Miyazaki, A.D., and Fernandez, A. (2001), 'Consumer perceptions of privacy and security risks for online shopping', The Journal of Consumer Affairs, Vol 35, No 1, pp 27-45.

Morrill, C., and Morrill, J. (2003), 'Internal auditors and the external audit: a transaction cost perspective', Managerial Auditing Journal, Vol 18, No 6/7, pp 490-504.

Morton, F. (2006), 'Consumer benefit from use of the Internet', Innovation Policy and the Economy, Vol 6, pp 67-90.

Oliver, R.L., and Burke, R. (1999), 'Expectation processes in satisfaction formation: a field study', Journal of Service Research, Vol 1, No 3, pp 196-214.

Phau, I., and Poon, S.M. (2000), 'Factors influencing the type of products and services purchased over the Internet', Internet Research: Electronic Networking Applications and Policy, Vol 10, No 2, pp $102-113$.

Picot, A., Bortenlänger, C., and Röhrl, H. (1997), 'Organization of electronic market: contributions from the new institutional economics', The Information Society, Vol 3, No 1, pp 107-123.

Ping, R. Jr (2004), 'On assuring valid measures for theoretical models using survey data', Journal of Business Research, Vol 57, pp 125-141.

Pitt, L.F., and Foreman, S.K. (1999), 'International marketing role on organizations', Journal of Business Research, Vol 44, No 1, pp 25-36.

Sriram, V., Krapfel, R., and Spekmen, R. (1992), 'Antecedents to buyer-seller collaboration: an analysis from the buyer's perspective', Journal of Business Research, Vol 25, pp 303-320.

Stanton, J.M. (1998), 'An empirical assessment of data collection using the Internet', Personnel Psychology, Vol 51, pp 709-725.

Strader, T., and Shaw, M.J. (1999), 'Consumer cost differences for traditional and Internet markets', Internet Research: Electronic Networking Applications and Policy, Vol 9, pp 82-92. 
Stump, R.L., and Heide, J.B. (1996), 'Controlling supplier opportunism in industrial relationships', Journal of Marketing Research, Vol 31, pp 431-441.

Suh, B., and Han, I. (2003), 'The impact of customer trust and perception of security control on the acceptance of electronic commerce', International Journal of Electronic Commerce, Vol 7, No 3, pp 135-161.

Surjadjaja, H., Ghosh, S., and Antony, J. (2003), 'Determining and assessing the determinant of eservice operations', Journal of Information Management and Computer Security, Vol 9, No 4, pp 146153.

Teo, T.S., and Yu, Y. (2005), 'Online buying behavior: a transaction cost economics perspective', Omega, Vol 33, No 5, pp 451-465.

Williamson, O.E. (1979), 'Transaction cost economics: the governance of contractual relations', Journal of Law and Economics, Vol 22, No 2, pp 233-261.

Williamson, O.E. (1981), 'The economics of organization: the transaction cost approach', American Journal of Sociology, Vol 87, No 3, pp 548-577.

Williamson, O.E. (1985), The Economic Institutions of Capitalism, Free Press, New York.

Wilson, N., and Zhang, H. (2002), 'Do organisational routines in manufacturing inform contracting choices in distribution?', Management Decision, Vol 40, No 1, pp 50-57.

Woodruff, R.B., and Gardial, S.F. (1996), Know Your Customer, Blackwell Publishers, Cambridge.

Wright, K.B. (2005), 'Researching internet-based populations: advantages and disadvantages of online survey research, online questionnaire authoring software packages, and web survey services', Journal of Computer-Mediated Communication, Vol 10, No 3, Article 11 (http://jcmc.indiana.edu/ vol10/issue 3/wright.html, accessed 21 July 2008).

Yoon, S.J. (2002), 'The antecedents and consequences of trust in online-purchase decision', Journal of Interactive Marketing, Vol 16, No 1, pp 47-63. 